\title{
Human Epidermal Growth Factor Receptor-2 gene polymorphism and breast cancer risk in women from the Northeastern region of Brazil
}

\author{
Carla Solange Escórcio-Dourado iD,' Francisco Adelton Alves-Ribeiro iD, ' Jose Charles Lima-Dourado iD,' \\ Alesse Ribeiro dos Santos (iD,' Renato de Oliveira Pereira (iD,' Cleciton Braga Tavares (iD,' Vladimir Costa \\ Silva (iD,' Pedro Vitor Lopes Costa iD,," José Maria Soares-Júnior (iD, "' Benedito Borges da Silva (iD) 1,II,* \\ 'Programa de Pos-Graduacao da Rede Nordeste de Biotecnologia (RENORBIO), Nordeste, Universidade Federal do Piaui, Teresina, PI, BR. "Programa de \\ Pos-Graduacao em Ciencias Medicas, Universidade Federal do Piaui, Teresina, PI, BR. 'I'Departamento de Obstetricia e Ginecologia, Hospital das Clinicas \\ (HCFMUSP), Faculdade de Medicina, Universidade de Sao Paulo, SP, BR.
}

Escórcio-Dourado CS, Alves-Ribeiro FA, Lima-Dourado JC, dos Santos AR, de Oliveira Pereira R, Tavares CB, et al. Human Epidermal Growth Factor Receptor-2 gene polymorphism and breast cancer risk in women from the Northeastern region of Brazil. Clinics. 2020;75:e2360

*Corresponding author. E-mail: beneditoborges@globo.com

OBJECTIVES: In the Human Epidermal Growth Factor Receptor-2 (HER2) rs1136201 variant, the presence of the G allele may promote cellular alterations and increase breast cancer risk, in addition to enhanced cellular proliferation, tumor aggressiveness, and metastases. The aim of this study was to investigate the presence of the single-nucleotide polymorphism (SNP) variant, rs1136201, within the HER2 gene in women from the Northeastern region of Brazil and breast cancer risk.

METHODS: The study included 140 women who were divided into two groups, case (breast cancer) and control (without breast cancer), with 70 women in each group. Peripheral blood of each woman was drawn for the study of genomic Deoxyribonucleic acid (DNA) extracted from leukocytes using the genotyping technique by real-time polymerase chain reaction.

RESULTS: The GG genotype occurred in 1 woman in both groups (1.4\%) ( $p=0.32)$, while the AG genotype occurred in $19(27.2 \%)$ and $13(18.6 \%)$ women in the case and control $(p=1.00)$ groups, respectively. No statistically significant difference in GG and AG genotypes was observed between the case and control groups in premenopausal women $(p=1.00)$. Furthermore, no significant difference in genotypes was observed between the groups, among postmenopausal women $(p=0.14)$.

CONCLUSION: In this study, the HER2 rs1136201 polymorphism did not show any statistically significant association with breast cancer, both in premenopausal and postmenopausal women. Nevertheless, further studies with a larger sample size should be performed to assess the association of HER2 polymorphism with breast cancer risk in women from the Northeastern region of Brazil.

KEYWORDS: Breast Cancer Risk; Genetic Polymorphism; HER2 rs1136201 Variant; Real-Time PCR.

\section{INTRODUCTION}

Breast cancer is a neoplasm that most commonly affects women worldwide, with an estimate of 2,088,849 new cases and 626,679 deaths in 2018 based on GLOBOCAN 2018 (1). Breast cancer incidence is higher in the most developed country of the world compared to underdeveloped countries $(2,3)$. In Brazil, following non-melanoma skin cancer, breast cancer is the most common malignancy in women, with an estimate of 59,700 new cases and 16,927 deaths in 2019 (4).

Copyright $\odot 2020$ CLINICS - This is an Open Access article distributed under the terms of the Creative Commons License (http://creativecommons.org/licenses/by/ 4.0/) which permits unrestricted use, distribution, and reproduction in any medium or format, provided the original work is properly cited.

No potential conflict of interest was reported.

Received for publication on August 24, 2020. Accepted for publication on October 23, 2020

DOI: $10.6061 /$ clinics/2020/e2360
Further, the Brazilian National Cancer Institute estimates approximately 66,280 new cases of breast cancer in Brazilian women for 2020 (5). Although physical examination and mammography are important for early diagnosis and to reduce mortality, in underdeveloped and developing countries such as Brazil, the disease is commonly diagnosed in advanced stages, resulting in high mortality rates (6-8). Despite early diagnosis and current therapeutic strategies that are important to reduce mortality, the estimate of breast cancer deaths in Brazil for 2020 is 17,572 cases (5).

Breast cancer is a disease of unknown etiology that involves multiple risk factors of which genetic alterations are the major ones (9). Alterations of human epidermal growth factor receptor 2 (HER2) proto-oncogene (also known as erbB-2 or HER2/neu) have been implicated in the carcinogenesis and prognosis of breast cancer; they have also been thought to play a critical role in both breast cancer development and progression $(10,11)$. Siddig et al. (12) have shown the association of breast cancer risk with single nucleotide polymorphism (SNP) in HER-2/neu, Ile655Val 
[db SNP rs1136200]. ERBB2 is a proto-oncogene, that is present at higher levels in premenopausal women and in estrogen receptor (ER) negative breast cancers than in ER positive breast cancers (13). The HER2 gene, located on chromosome $17 q 21$, is a member of the human epidermal growth factor receptor family. Breast cancers that overexpress HER2 are an aggressive molecular subtype, exhibiting rapid tumor growth, increased risk of postoperative recurrence, resistance to hormone therapy, and poor response to conventional breast carcinoma chemotherapy (13).

SNP in the HER2 gene is one of the most important genetic alterations in breast cancer (14). Various studies on genotyping have correlated HER2 Ile655Val (rs1136201 variant) polymorphism and breast cancer risk (10-12), while other authors have not shown an increased risk for breast cancer in women with HER2 Ile655Val (rs1136201) polymorphism (15). Thus, the results have been inconsistent and conflicting, despite the fact that the majority of authors have suggested a positive association between the presence of HER2 rs1136201 polymorphism and risk of breast cancer development (10$12,14)$. These controversies over the HER2 rs1136201 polymorphism and breast cancer risk motivated us to design the current study.

\section{MATERIAL AND METHODS}

\section{Patients and blood samples}

The Internal Review Board of the Federal University of Piaui approved the study under number 43447015.8. 0000.5214 and all patients signed an informed consent form prior to admission. This is a controlled cross-sectional study, involving patients managed in the Breast Disorders Outpatient Clinic of the Getulio Vargas (HGV) Hospital and Laboratory of Molecular Biology of the Natan Portella Hospital, Federal University of Piaui, Brazil, from March 2016 to December 2018. The study included 140 women, divided into two groups of 70 women each: case group (with breast cancer) and control group (without breast cancer). In fact, considering the asymptotic test to compare two sample proportions if the true proportions were $p 1=0.32$ and $p 2=0.2$, the sample sizes would be $n 1=n 2=70$, with a $5 \%$ level of significance. The power of the two-sided test would be only $37 \%$ and a on-sided test would have a statistical power of $49 \%$. The low power is the main caveat of this study. Patients with histologically confirmed breast cancer and healthy patients (controls) that were negative for malignancy were included in the sutdy, as confirmed by physical examination and imaging tests. Women older than 80 years and patients suffering from liver, metabolic, cardiovascular, kidney disease or those reporting other types of malignancies were excluded from the study. A volume of $3 \mathrm{~mL}$ of blood was drawn using disposable syringes and needles by a specialized technician, after the patient received medical consultation. Whole blood was stored in proper vials containing anticoagulant (EDTA) and stored in a freezer at $-20{ }^{\circ} \mathrm{C}$. All women in the study were instructed not to use antiinflammatory drugs during the $72 \mathrm{~h}$ before blood sample collection.

\section{DNA extraction}

For DNA extraction of sample leukocytes, the PureLink Genomic $^{\circledR}$ DNA Mini Kit (Life Technologies) was used, following manufacturer's instructions.

\section{Genotyping}

After isolation, DNA concentration was determined by Nanodrop2000 spectrophotometer (Thermo Fisher Scientific, Waltham, MA, USA). Genotyping was performed by realtime polymerase chain reaction (qPCR). Absolute DNA quantification of a sample is performed with the use of a standard curve, obtained by amplification of known quantities of the same DNA. SNP genotyping assays contain a probe labeled with $\mathrm{VIC}^{\circledR}$ dye and a probe labeled with FAM $^{\mathrm{TM}}$ dye. TaqMan ${ }^{\mathbb{R}}$ probes incorporate minor groove binder (MGB) technology, where the $\mathrm{VIC}^{\circledR}$ probe detects allele 1 and the FAM ${ }^{\mathrm{TM}}$ probe detects allele 2 . The reactions were conducted in final volumes of $20 \mu \mathrm{L}$ per patient, containing: $10 \mu \mathrm{L}$ TaqMan ${ }^{\circledR}$ Genotyping Master Mix; $0.5 \mu \mathrm{L}$ of TaqMan ${ }^{\circledR}$ probe customized for SNP genotyping of HER2 human gene (SNP ID rs1136201.Cod.C__7452451_1_Context sequence VIC/FAM (5' fluorescent reporter dye):CGCCCCCA GCCCTCTGACGTCCATC[A/G]TCTCTGCGGTGGTTGGCA TTCTGCT) (Table 1); $5.5 \mu \mathrm{L}$ deionized DNA/RNA-free water and $4 \mu \mathrm{L}$ DNA sample per patient; these volumes were distributed in 96-well reaction plates (MicroAmp_ Fast Optical 96Well Reaction Plate) with $0.1 \mathrm{~mL}$ per plate (Applied Biosystems, EUA) and in duplicates. Amplification was performed using the Fast Real-Time PCR System 7500 with the SDS 2.2 software incorporated for SNP genotyping (Applied Biosystems, EUA) in the following steps: (1) pre-PCR step for $1 \mathrm{~min}$ at $60^{\circ} \mathrm{C}$; (2) preincubation of the reaction mixture at $95{ }^{\circ} \mathrm{C}$ for $10 \mathrm{~min}$; (3) thermocycling at $95^{\circ} \mathrm{C}$ for $15 \mathrm{~s}$ and $60{ }^{\circ} \mathrm{C}$ for $60 \mathrm{~s}$ for 40 cycles; and (4) post-PCR step for $1 \mathrm{~min}$ at $60^{\circ} \mathrm{C}$. Fluorescence data were captured during 40 reaction cycles. Quality control of qPCR was assessed by random selection of $20 \%$ of the total samples for re-genotyping by an independent technician.

\section{Statistical analysis}

The Chi-square test was used to determine whether genotype distribution conformed to Hardy-Weinberg equilibrium. Genotype frequency was compared between women with breast cancer and women without the disease from a control group, using Fisher's exact test. The odds ratio (OR) and $95 \%$ confidence interval (CI) were calculated using Fisher's exact test due to low frequencies in lines. Statistical significance was set at $p<0.05$.

\section{RESULTS}

The study included 140 women (70 cases and 70 controls). Mean patient age and standard deviation was $49.1 \pm 11.1$ years for cases and $45.4 \pm 12.8$ for controls. Genotype frequencies of the rs1136201 variant of the HER2 gene conformed to Hardy-Weinberg equilibrium. The GG genotype was present in one woman $(1.4 \%)$ in the case and control groups $(p=0.32)$, while the AG genotype occurred in $19(27.2 \%)$ women from the case group and in $23(32.9 \%)$ women from the control group $(p=1.00)$ (Table 2). After stratification according to menopausal status, no statistically significant difference in GG and AG genotypes was observed

Table 1 - Identification of gene codes and SNP used in TaqMan $\mathbb{R}$ assay Source Life Technologies.

\begin{tabular}{lc}
\hline Gene variant HER2 & Sequence context VIC/FAM \\
\hline rs1136201 A > G & CGCCCCCAGCCCTCTGACGTCCATC[A/G] \\
& TCTCTGCGGTGGTTGGCATTCTGCT \\
\hline
\end{tabular}


Table 2 - Patient characteristics and genotyping of HER2 gene SNP rs1136201 in case and control patients.

\begin{tabular}{|c|c|c|c|c|}
\hline Characteristics & Case & Control & & \\
\hline $\mathrm{N}$ & 70 & 70 & & \\
\hline Mean age (SD) & $49.1( \pm 11.1)$ & $45.4( \pm 12.8)$ & & \\
\hline Premenopausal & 39 & 33 & & \\
\hline \multirow[t]{2}{*}{ Postmenopausal } & 31 & 37 & & \\
\hline & Case (\%) & Control (\%) & $p$ & OR (95\% Cl) \\
\hline \multicolumn{5}{|l|}{ rs1136201 } \\
\hline AA & $50(71.4)$ & $46(65.7)$ & - & 1 \\
\hline$A G$ & 19 (27.2) & $23(32.9)$ & 1 & $1.08(0.34-3.4)$ \\
\hline GG & $1(1.4)$ & $1(1.4)$ & 0.32 & $1.59(0.68-3.81)$ \\
\hline
\end{tabular}

There was no statistically significant difference of SNP genotype rs1136201 between case and control groups $(p>0.05)$. The odds ratio (OR) was not significantly higher between groups.

Table 3 - Genotyping of HER2 gene SNP rs1136201 in premenopausal and postmenopausal women.

\begin{tabular}{|c|c|c|c|c|c|c|c|c|}
\hline & \multicolumn{4}{|c|}{ Premenopausal } & \multicolumn{4}{|c|}{ Postmenopausal } \\
\hline & Case & Control & $p$ & OR $(95 \% \mathrm{Cl})$ & Case & Control & $p$ & OR $(95 \% \mathrm{Cl})$ \\
\hline AA & 30 & 26 & - & 1 & 20 & 20 & - & 1 \\
\hline$A / G$ & 8 & 6 & 0.7 & $1.1(0.34-3.4)$ & 11 & 17 & 0.14 & $2.7(0.6-13.6)$ \\
\hline GG & 1 & 1 & 1 & $1.4(0.23-4.3)$ & 0 & 0 & - & - \\
\hline
\end{tabular}

There was no statistically significant difference between SNP genotypes rs 1136201 in the case group and control group ( $p>0.05)$, as well as in the postmenopausal group $(p>0.05)$. There was no significantly higher odds ratio (OR).

between the case and control groups in premenopausal women $(p=1.00)$. In addition, no significant difference was found between postmenopausal women from the case and control groups $(p=0.14)$ (Table 3$)$.

\section{DISCUSSION}

The Brazilian population is constituted by a rich racial miscegenation, mainly composed of European descendants, African and indigenous populations. Therefore, as in other countries with a different racial pattern, the distributions of genetic variants in the Brazilian population commonly do not show a consistent genetic pattern (9). HER2 gene is found amplified in tumors and some authors showed that single nucleotide polymorphism at codon 655 (Ile655Val) is not associated with an increase in breast cancer risk (16), while other authors suggest that HER2 Ile 655Val polymorphism may contribute to breast cancer risk (17). In addition to these controversies, to the best of knowledge, there is a scarcity of studies on HER2 gene polymorphism, particularly its rs1136201 variant, associated with breast cancer risk in women from Northeastern Brazil. The current study did not show statistically significant differences between genotypes of case and control groups. It also did not show any differences in premenopausal and postmenopausal women for the rs1136201 variant of the HER2 gene between the above-mentioned groups.

In cancer, HER2 may be deregulated by a variety of mechanisms, including mutations, HER2 polymorphism, HER2 overexpression, and overproduction of ligands for HER2 activation (18). Analyses of human DNA clones identified polymorphism at codon 655 in the transmembrane coding region of the HER2 gene, which encodes isoleucine (Ile; ATC) or valine (Val; GTC) and has been reported in different types of cancer. The presence of Val $(G)$ in the transmembrane position stabilizes the formation of an active dimer of the protein that predisposes HER2 to auto-activity (19). In addition, Takano et al. (20) suggested that the Ile
(A) to Val (G) that change in the HER2 codon 655 may alter hydrophobicity of the HER2 protein, affecting the conformational stability of the hydrophobic domains within the transmembrane domain. Likewise, some authors have suggested that the presence of this polymorphism in cancer enhances dimerization, self-phosphorylation, and HER2 tyrosine kinase activity, which may cause cell transformation (21).

A case-control study of HER2 Ile655Val including Chinese women suggested that the GG homozygote was associated with an increased risk for breast cancer (10). Lee et al. (22) investigated the HER2 Ile655Val SNP in Taiwanese women with early breast cancer and suggested that the presence of GG genotype may be a risk factor for early-onset breast cancer. Likewise, other authors have suggested that the presence of GG homozygote may be a risk factor for breast cancer in Caucasian populations and in African women $(23,24)$. Ma et al. (25) showed that the heterozygous AG genotype had a modest association with breast cancer risk. Nevertheless, some authors show that the SNP rs1136201 of the HER2 gene was not associated with an increased breast cancer risk (16); corroborating these findings, Breyer et al. (26) did not observe any association between this SNP and breast cancer risk.

Thus, some authors hypothesized that the HER2 Ile655Val polymorphism may be considered a genetic biomarker of susceptibility to breast cancer risk, although it is not reliable for the estimation of tumor aggressiveness. However, the association between the HER2 Ile655Val (rs1136201) SNP and breast cancer risk has still not been fully elucidated (27). Furrer et al. (28) studied the association between this polymorphism and non-metastatic HER2-positive breast cancer; they theorized that the HER2 Ile655Val SNP may play a significant role in breast carcinogenesis in Caucasian women. In contrast, Watrowski et al. (15) did not show any association between this SNP and susceptibility to breast cancer in Caucasian women.

Several authors have shown conflicting results regarding the association between the HER2 and breast cancer; HER2 
has somatic variations in different ethnicities (6). Our results are in agreement with Ile655Val SNP and breast cancer risk $(15,16,26)$. Nevertheless, it is important to bear in mind that these studies have been conducted in different ethnic groups with genetic polymorphisms composed of descendants of European, African and Asian with different genetic patterns (9). Likewise, in Brazil, it was not shown presence of significant difference of HER2 polymorphism between breast cancer women and controls, probably due to racial widespread miscegenation without a consistent genetic pattern and also sample size.

\section{CONCLUSIONS}

Therefore, in this study, there was no significant association observed between the SNP rs1136201 variant of the HER2 gene and breast cancer risk in both premenopausal and postmenopausal women from the Northeastern region of Brazil. Nevertheless, owing to the high degree of racial miscegenation in Brazil, further studies with a higher statistical power and a larger sample size are warranted.

\section{ACKNOWLEDGEMENTS}

The authors thank the patients who participated in the current study and the Postgraduate Program of the Northeast Network of Biotechnology (RENORBIO) Northeast, Brazil.

\section{AUTHOR CONTRIBUTIONS}

Escórcio-Dourado CS, Alves-Ribeiro FA, Lima-Dourado JC, da Silva BB conceived the study idea, interpreted the data, wrote and revised the manuscript. dos Santos AR, de Oliveira Pereira R, Tavares CB participated in the design, coordination of the study, interpreted the data, wrote and revised the manuscript. Silva VC, Costa PV collected the materials and conducted data extraction. Soares-Júnior JM, da Silva BB analyzed, interpreted the data and revised the manuscript. All authors have read and approved the manuscript.

\section{REFERENCES}

1. Ferlay J, Colombet M, Soerjomataram I, Mathers C, Parkin DM, Piñeros $\mathrm{M}$, et al. Estimating the global cancer incidence and mortality in 2018: GLOBOCAN sources and methods. Int J Cancer. 2019;144(8):1941-53. https://doi.org/10.1002/ijc.31937

2. Borges US, Costa-Silva DR, da Silva-Sampaio JP, Escórcio-Dourado CS, Conde AM Jr, Campelo V, et al. A comparative study of Ki-67 antigen expression between luminal $\mathrm{A}$ and triple-negative subtypes of breast cancer. Med Oncol. 2017;34(9):156. https://doi.org/10.1007/s12032-0171019-x

3. Barros-Oliveira MDC, Costa-Silva DR, Campos-Verdes LC, Pereira RO, Silva RA, Moura-Borges PT, et al. CYP19A1 gene expression in the peripheral blood of Brazilian women with breast cancer relapse. BMC Cancer. 2020;20(1):480. https://doi.org/10.1186/s12885-020-06978-z

4. Quintanilha LF, Souza LN, Sanches D, Demarco RS, Fukutani KF. The impact of cancer campaigns in Brazil: a Google Trends analysis. Ecancermedicalscience. 2019;13:963. https://doi.org/10.3332/ecancer.2019.963

5. Estimate/2020 - Incidence of Cancer in Brazil. National Cancer Institute. https: / / www.inca.gov.br/sites/ufu.sti.inca.local/files//media/docu ment/ / estimativa-2020-incidencia-de-cancer-no-brasil.pdf

6. Sampaio FA, Martins LM, Dourado CSME, Revoredo CMS, Costa-Silva DR, Oliveira VA, et al. A case-control study of Metallothionein-1 expression in breast cancer and breast fibroadenoma. Sci Rep. 2019;9(1): 7407. https: / / doi.org/10.1038/s41598-019-43565-0

7. Simplicio-Revoredo CM, de Oliveira Pereira $\mathrm{R}$, de Almeida Melo $\mathrm{M}$, Lopes-Costa PV, de Tarso Moura-Borges P, Sousa EB, et al. Expression of Nrf2 and NF- $\mathrm{KB}$ transcription factors in breast cancer and breast fibroadenoma: Insights for a new therapeutic approach. Oncotarget. 2020; 11(18):1629-36. https://doi.org/10.18632/oncotarget.27574

8. Pereira RO, Luz LAD, Chagas DC, Amorim JR, Nery-Júnior EJ, Alves $\mathrm{ACBR}$, et al. Evaluation of the accuracy of mammography, ultrasound and magnetic resonance imaging in suspect breast lesions. Clinics. 2020;75:e1805. https://doi.org/10.6061/clinics/2020/e1805

9. Costa-Silva DR, da Conceição Barros-Oliveira M, Borges RS, CamposVerdes LM, da Silva-Sampaio JP, Escorcio-Dourado CS, et al. Insulin-like growth factor 1 gene polymorphism in women with breast cancer. Med Oncol. 2017;34(4):59. https://doi.org/10.1007/s12032-017-0915-4

10. Xie D, Shu XO, Deng Z, Wen WQ, Creek KE, Dai Q, et al. Populationbased, case-control study of HER2 genetic polymorphism and breast cancer risk. J Natl Cancer Inst. 2000;92(5):412-7. https://doi.org/10.1093/ jnci/92.5.412

11. Kallel I, Kharrat N, Al-fadhly S, Rebai M, Khabir A, Boudawara TS, et al. HER2 polymorphisms and breast cancer in Tunisian women. Genet Test Mol Biomarkers. 2010;14(1):29-35. https://doi.org/10.1089/gtmb. 2009.0069

12. Siddig A, Mohamed AO, Kamal H, Awad S, Hassan AH, Zilahi E, et al. HER-2/neu Ile655Val polymorphism and the risk of breast cancer. Ann N Y Acad Sci. 2008;1138:84-94. https://doi.org/10.1196/annals. 1414.014

13. Révillion F, Bonneterre J, Peyrat JP. ERBB2 oncogene in human breast cancer and its clinical significance. Eur J Cancer. 1998;34(6):791-808. https://doi.org/10.1016/S0959-8049(97)10157-5

14. McKean-Cowdin R, Kolonel LN, Press MF, Pike MC, Henderson BE. Germ-line HER-2 variant and breast cancer risk by stage of disease. Cancer Res. 2001;61(23):8393-4.

15. Watrowski R, Castillo-Tong DC, Wolf A, Schuster E, Fischer MB, Speiser P, et al. HER2 Codon 655 (Ile/Val) Polymorphism and Breast Cancer in Austrian Women. Anticancer Res. 2015;35(11):5901-4.

16. Cox DG, Hankinson SE, Hunter DJ. The erbB2/HER2/neu receptor polymorphism Ile655Val and breast cancer risk. Pharmacogenet Genomics. 2005;15(7):447-50. https://doi.org/10.1097/01.fpc.0000166822.66754.c6

17. Lu S, Wang Z, Liu H, Hao X. HER2 Ile655Val polymorphism contributes to breast cancer risk: evidence from 27 case-control studies. Breast Cancer Res Treat. 2010;124(3):771-8. Erratum in: Breast Cancer Res Treat. 2012; 131(1):353. https://doi.org/10.1007/s10549-010-1196-1

18. Earp HS, Dawson TL, Li X, Yu H. Heterodimerization and functional interaction between EGF receptor family members: a new signaling paradigm with implications for breast cancer research. Breast Cancer Res Treat. 1995;35(1):115-32. https://doi.org/10.1007/BF00694752

19. Fleishman SJ, Schlessinger J, Ben-Tal N. A putative molecular-activation switch in the transmembrane domain of erbB2. Proc Natl Acad Sci U S A. 2002;99(25):15937-40. https://doi.org/10.1073/pnas.252640799

20. Takano K, Ogasahara K, Kaneda H, Yamagata Y, Fujii S, Kanaya E, et al. Contribution of hydrophobic residues to the stability of human lysozyme: calorimetric studies and X-ray structural analysis of the five isoleucine to valine mutants. J Mol Biol. 1995;254(1):62-76. https://doi.org/10.1006/ jmbi.1995.0599

21. Nakajima M, Sawada H, Yamada Y, Watanabe A, Tatsumi M, Yamashita J, et al. The prognostic significance of amplification and overexpression of cmet and c-erb B-2 in human gastric carcinomas. Cancer. 1999;85(9):1894902. https://doi.org/10.1002/(SICI)1097-0142(19990501)85:9<1894::AIDCNCR3 > 3.0.CO;2-J

22. Lee SC, Hou MF, Hsieh PC, Wu SH, Hou LA, Ma H, et al. A case-control study of the HER2 Ile655Val polymorphism and risk of breast cancer in Taiwan. Clin Biochem. 2008;41(3):121-5. https://doi.org/10.1016/ j.clinbiochem.2007.11.005

23. Lu S, Wang Z, Liu H, Hao X. HER2 Ile655Val polymorphism contributes to breast cancer risk: evidence from 27 case-control studies. Breast Cancer Res Treat. 2010;124(3):771-8. Erratum in: Breast Cancer Res Treat. 2012; 131(1):353. https://doi.org/10.1007/s10549-010-1196-1

24. Wang H, Liu L, Lang Z, Guo S, Gong H, Guan H, et al. Polymorphisms of ERBB2 and breast cancer risk: a meta-analysis of 26 studies involving 35,088 subjects. J Surg Oncol. 2013;108(6):337-41. https://doi.org/10.1002/ jso. 23386

25. Ma Y, Yang J, Zhang P, Liu Z, Yang Z, Qin H. Lack of association between HER2 codon 655 polymorphism and breast cancer susceptibility: meta-analysis of 22 studies involving 19,341 subjects. Breast Cancer Res Treat. 2011 Jan;125(1):237-41. https://doi.org/10.1007/s10549-0100965-1

26. Breyer JP, Sanders ME, Airey DC, Cai Q, Yaspan BL, Schuyler PA, et al. Heritable variation of ERBB2 and breast cancer risk. Cancer Epidemiol Biomarkers Prev. 2009;18(4):1252-8. https://doi.org/10.1158/1055-9965. EPI-08-1202

27. Dahabreh IJ, Murray S. Lack of replication for the association between HER2 I655V polymorphism and breast cancer risk: a systematic review and meta-analysis. Cancer Epidemiol. 2011;35(6):503-9. https://doi.org/ 10.1016/j.canep.2011.01.007

28. Furrer D, Lemieux J, Côté MA, Provencher L, Laflamme C, Barabé F, et al. Evaluation of human epidermal growth factor receptor 2 (HER2) single nucleotide polymorphisms (SNPs) in normal and breast tumor tissues and their link with breast cancer prognostic factors. Breast. 2016;30:191-196. https://doi.org/10.1016/j.breast.2016.09.014 